\section{Estudo \\ CoDebate}

em Testão

Dlanejamento

\title{
ANÁLISE DA QUALIDADE DE VIDA PELO MÉTODO WHOQOL- BREF: ESTUDO DE CASO NA CIDADE DE CURITIBA, PARANÁ
}

\author{
Larissa Maria da Silva Ferentz ${ }^{1}$
}

\begin{abstract}
Resumo: A qualidade de vida vem se mostrando um importante parâmetro a ser considerado no planejamento urbano das cidades, de modo que se faça presente o conhecimento sobre os problemas enfrentados no dia-adia das pessoas a partir da sua percepção. Desta forma, foi adotado um estudo de caso amostral na cidade de Curitiba/PR através do método de Qualidade de Vida da Organização Mundial de Saúde-Breve (WHOQOL$\mathrm{BREF}$ ). O índice WHOQOL-BREF, tem sua aplicação por meio de questionários, os quais totalizaram uma amostra estratificada de 425 cidadãos para aplicação do presente instrumento de pesquisa, em escala Likert de cinco pontos. A qualidade de vida da cidade de Curitiba teve como média geral 3,62, permanecendo em uma classificaçâo entre "regular" e "bom". A partir dos dados quantitativos, foi possível identificar as regióes mais críticas referente a qualidade de vida, estando estas localizadas, em sua maior área, na região sul da cidade. Utilizando a opinião da populaçáo, também pode-se identificar quais são as mudanças prioritárias a serem executadas em cada local, desde melhorias no transporte, criaçáo de parques, até a despoluição de rios.
\end{abstract}

Palavras-chave: Indicador. Qualidade de Vida. WHOQOL-BREF.

\section{QUALITY OF LIFE OF THE METHODO WHOQOL-BREF: A CASE STUDY IN CURITIBA CITY}

\begin{abstract}
The quality of life has proven to be an important parameter to be considered in the urban planning of cities, so that the knowledge becomes present about the problems faced in the daily life of people from their perception. Thus, a case study was adopted in the city of Curitiba/PR through the Quality of Life method of the World Health Organization-Brief (WHOQOL-BREF). The WHOQOL-BREF index has its application through questionnaires, which totaled in a stratified sample of 425 citizens for the application of this research instrument, in Likert scale of five points. Curitiba's quality of life had a general average of 3.62, remaining in a classification between "regular" and "good". From the quantitative data, it was possible to identify the most critical regions related to the quality of life, being these located, in their greater area, in the south region of the city. Using the opinion of the population, it is also possible to identify the priority changes to be carried out at each location, from improvements in transportation, creation of parks, to the depollution of rivers.
\end{abstract}

Keywords: Indicator. Quality of life. WHOQOL-BREF.

1 Engenheira Ambiental. Mestranda em Gestão Urbana da Pontifícia Universidade Católica do Paraná (PUCPR). E-mail: ferentzengenharia@gmail.com 


\section{INTRODUÇÁO}

O termo Qualidade de Vida (QV) foi inicialmente inserido no contexto político pelo até então presidente dos Estados Unidos, Lyndon Johnson, em 1964. Ele afirmou que "os objetivos nấo podem ser medidos através do balanço dos bancos. Eles só podem ser medidos através da qualidade de vida que proporcionam às pessoas" (FLECK et al., 1999, p. 03). Neste período a menção à QV era parte dos meios políticos, sendo relacionada com o desenvolvimento econômico apenas mais tarde. No livro Le Calidad de Vida de Nussbaum e Sen (1996), a abordagem era de que, além dos indicadores econômicos, os quais são pertencentes ao desenvolvimento, deve-se analisar também os desejos, as emoçóes e as capacitaçóes das pessoas.

Esta concepção é reforçada por Schneider e Freitas (2013, p. 122), ao afirmarem que o progresso pode proporcionar melhorias na qualidade de vida, principalmente quando há uma redução na vulnerabilidade da sociedade. Quanto maior é a satisfação das pessoas com as necessidades básicas, melhor será seu desenvolvimento na qualidade de vida. Essas necessidades são consideradas de direito de cada cidadáo, sendo dever do governo atender prioritariamente a seis delas: alimentação, saúde física e mental, habitação, emprego, renda para as necessidades básicas, alfabetização e conhecimento dos direitos civis (WILHEIM, 1982).

Por outro lado, alguns autores também consideram uma visão imaterial sobre a ótica da qualidade de vida. Para Demo (2001, p. 45), a QV é um instrumento de avaliação, onde "[...] não vale o maior, mas o melhor; não o extenso, mas o intenso; não o violento, mas o envolvente; não a pressão, mas a impregnação". Gill e Feistein (1994) também afirmam que além do bem-estar físico e emocional, é importante considerar a família, os amigos e as circunstâncias que as pessoas passam em sua vida. Desta forma, pode-se notar que a qualidade de vida abrange diversos setores da sociedade, sendo seus conceitos bem distintos e abrangentes.

Ela pode apresentar-se nas áreas de saúde, bem-estar, ética, estilo de vida, felicidade, dentre outros, onde cada um deve ser analisado individualmente com suas delimitaçóes para melhor entendimento (PEREIRA; TEIXEIRA; SANTOS, 2012, p. 241). Sendo assim, pode ser classificada como um tema abstrato, de forma que cada pessoa possui o seu ponto de vista e o mesmo reflete diretamente na sua definição. Ainda hoje não existe um conceito padrão, de modo que ela existe quando se possui "um mínimo de condições para que os indivíduos nela inseridos possam desenvolver o máximo de suas potencialidades, sejam estas: viver, sentir, amar, trabalhar, produzindo bens e serviços, fazendo ciência ou artes" (RUFFINO NETTO, 1992, p. 64). Ou seja, quanto mais oportunidades houver para as pessoas se desenvolverem, maior será sua qualidade de vida.

Com o processo de urbanização, muitos problemas iniciaram nas cidades, e com eles as alterações na QV também tem se apresentado cada vez mais sérias em escalas estruturais, físicas e psicológicas (PUPPI, 1981). Um exemplo disto são as áreas habitadas pela população de baixa renda, onde em sua maioria, se caracterizam como locais sujeitos a inundaçóes, enchentes, deslizamentos, contaminaçôes, dentre outros riscos (GRAZIA et al., 2001). Isto decorre de um planejamento mal estruturado, onde não se deu devida atenção ao meio urbano. 
Ao se olhar para o passado, pode-se perceber que "[...] cidades e vilas foram se formando sem um plano pré-estabelecido, irrompendo de forma mais ou menos espontânea em locais arbitrários" (PUPPI, 1981, p. 10). Isto tem influenciado diretamente no dia a dia das pessoas, de forma que os serviços oferecidos pelas cidades seja o transporte, áreas verdes, oferta de saneamento básico, segurança, dentre outros aspectos, causam interferência na qualidade de vida da população. Deste modo, destaca-se a importância de considerar a opinião das pessoas para a formulação do planejamento urbano, pois são elas que vivenciam os problemas diariamente, assim como podem apresentar alternativas para soluçóes dos mesmos, economizando tempo e recursos financeiros dos órgáos responsáveis.

\section{REFERENCIAL TEÓRICO}

Neste momento, cabe destacar dois importantes fatores a serem relacionados: Planejamento Urbano e Qualidade de Vida.

\subsection{Planejamento Urbano}

As condiçóes criadas para o desenvolvimento urbano foram de responsabilidade do Estado no Brasil, no tempo em que o crescimento desenfreado da população já estava ocorrendo (MENEZES, 2001). Essa característica, segundo este autor, se difere do que aconteceu com os países desenvolvidos, onde o desenvolvimento urbano foi financiado pela iniciativa privada. No país, o desenvolvimento urbano era baseado no esquema viário, não dando atenção à qualidade de vida das pessoas, nem a saúde pública em geral. Devido a este fator, com o tempo iniciou-se o agravamento dos problemas nas cidades, sendo estes relacionados aos meios social, econômico e ambiental (PUPPI, 1981).

A partir do momento em que há uma sobrecarga do sistema e do aumento intenso de problemas urbanos, pode-se analisar a falha que se teve no planejamento e em sua gestáo. "O planejamento urbano deve ter metas e objetivos claros para que, a partir dos mesmos, sejam feitas propostas coerentes para determinada cidade [...]" (BARBOSA, 2008, p. 137). Duarte (2007) também traz esta visão em seu conceito, onde o planejamento deve possuir medidas para se atingir os objetivos, considerando os recursos financeiros e os fatores que podem influenciar no processo. "Nesse sentido, podemos dizer que o planejamento reconhece, localiza as tendências ou as propensôes naturais (locais e regionais) para o desenvolvimento" (DUARTE, 2007, p. 22).

Além disto, o planejamento deve buscar o equilíbrio entre o econômico, o social e o ambiental, de forma que o desenvolvimento das cidades seja em sua totalidade sustentável com a oportunidade de uma vida digna e saudável para as pessoas (IPPUC, 1992). Neste sentido, entende-se que no passado o planejamento era visto como um instrumento para crescimento e desenvolvimento econômico, sem se ater em objetivos direcionados ao desenvolvimento mais equilibrado das cidades. Porém, atualmente esta visão vem mudando e se aperfeiçoando cada vez mais, pois a cidade é vista como um organismo vivo com suas diversas transformaçóes, e sendo assim, o planejamento "[...] acontece quando são buscadas soluçôes e alternativas não para a situação atual, mas para a situação que deverá ser" (DUARTE, 2007, p. 29). 


\subsection{Qualidade de Vida}

Com a busca por soluçóes dos problemas enfrentados nas cidades, a qualidade de vida vem sendo um tópico muito destacado atualmente. Fernandes (2000) ressalta que além do meio econômico e social, deve ocorrer um equilíbrio entre a natureza e o espaço urbano, pois embora os outros autores reforcem a relação apenas entre dois meios, ainda é necessário considerar outros setores da sociedade. Minayo, Hartz e Buss (2000) complementam esta visão ao afirmar que a qualidade de vida tem sido aproximada da satisfação, a qual pode ser encontrada nas relaçóes sociais, familiares, amorosas e ambientais.

Como pode-se observar, para eles, além das oportunidades que a sociedade possui de se desenvolver e das características locais de onde vivem, é importante ressaltar também os valores e os conhecimentos adquiridos pelas pessoas. Além disto, Minayo, Hartz e Buss (2000, p. 08) também reforçam que o termo qualidade de vida possui uma grande abrangência de significados, os quais "[...] refletem conhecimentos, experiências e valores de indivíduos e coletividades que a ele se reportam em variadas épocas, espaços e histórias diferentes, sendo, portanto, uma construção social com a marca da relatividade cultural". Englobando todos estes setores, Herculano, Porto e Freitas (2000, p. 237) propóem a seguinte definição:

[...] 'qualidade de vida' seja definida como a soma das condiçóes econômicas, ambientais, científico-culturais e políticas coletivamente construídas e postas à disposição dos indivíduos para que estes possam realizar suas potencialidades: inclui a acessibilidade à produção e ao consumo aos meios para produzir cultura, ciência e arte, bem como pressupóe a existência de mecanismos de comunicaçáo, de informação, de participaçáo e de influência nos destinos coletivos, através da gestão territorial que assegura água e ar limpos, higidez ambiental, equipamentos coletivos urbanos, alimentos saudáveis e a disponibilidade de espaços naturais amenos urbanos, bem como da preservação de ecossistemas naturais.

Observa-se que não existe um conceito padrão para a qualidade de vida. Ele varia de acordo com cada setor que será destinado, sendo totalmente dinâmico (SANTOS; RIBEIRO, 2001). Deste modo, ela pode ser classificada como um tema abstrato, de forma que cada pessoa possui o seu ponto de vista e o mesmo reflete diretamente na sua definição. Nesta pesquisa, adotou-se a definição desenvolvida pela Organização Mundial de Saúde (OMS): "a percepção do indivíduo de sua posição na vida no contexto da cultura e sistema de valores nos quais ele vive e em relação aos seus objetivos, expectativas, padróes e preocupaçóes" (WHO, 1997, p. 03).

A avaliação da QV da população é proposta por Herculano (2000) de duas formas: identificando os recursos disponíveis e acompanhando os indicadores para se certificar que os mesmos atendem as necessidades de um determinado grupo social e avaliando as necessidades das pessoas através dos desejos e da satisfação das mesmas perante a sociedade, pois desta maneira é possível manter um equilíbrio entre o que se possui e o que poderá ser alcançado com planejamento. Por outro lado, Fleck (2008) destaca seis grandes vertentes para serem consideradas: estudos sobre a felicidade e o bem-estar; busca de indicadores sociais; insuficiência das medidas objetivas de desfecho em saúde; psicologia positiva; satisfação do cliente; e movimento de humanização. 
Com base nesses parâmetros, a escolha de indicadores para medir a qualidade de vida dependerá da área de estudo a qual eles serão destinados. Para Wilheim (1982. p. 4) estes fatores apresentaráo variaçóes "[...] em funçáo de expectativas culturais, da abrangência de informaçóes, das características do grupo social, do nível educacional e, portanto, do nível de renda”. Enquanto que para Patrick (2008) estarão relacionados com as funçôes físicas, psicológicas, sociais, percepçóes, sensaçóes e oportunidades. Visando a padronização, a OMS criou um instrumento para se avaliar a qualidade de vida, de forma a possibilitar a comparação dos resultados entre diferentes situaçōes, setores ou regiōes.

O World Health Organization Quality of Life (WHOQOL) foi criado por 15 centros distintos no mundo e em 20 idiomas, sendo sua sede no Brasil, localizada no Rio Grande do Sul. A versão em português foi desenvolvida no Centro WHOQOL da Universidade Federal do Rio Grande do Sul (UFRGS). Este instrumento permite comparar estudos realizados em diferentes regióes. Dentro do WHOQOL existem cinco métodos oficiais de medição, sendo o WHOQOL-100, WHOQOL-BREF (abreviado), WHOQOL-HIV (para portadores do vírus HIV), WHOQOL-SRPB (foco na espiritualidade, religiáo e crenças pessoais) e WHOQOL-OLD (para idosos). Quando é necessário implantar novas políticas, é importante conhecer os efeitos e as alteraçóes que podem vir a ocorrer na qualidade de vida das pessoas, por isso o WHOQOL é um dos instrumentos que permitem monitorar tais mudanças (WHO, 1997), sendo importante para o planejamento das cidades.

\section{METODOLOGIA}

O projeto pioneiro da OMS foi o WHOQOL-100, composto por 100 questóes e constituído pelos domínios físico, psicológico, nível de Independência, relaçóes sociais, meio ambiente e aspectos espirituais/religiáo/crenças pessoais. Devido ao elevado número de perguntas e consequentemente pela demanda de tempo para reponde-las, a OMS abreviou o método original para o WHOQOL-BREF, o qual foi resumido para 26 questóes (ANEXO A). A nova estrutura se deu pela subdivisão de perguntas sobre a qualidade de vida geral (número um e a número dois) e o restante em quatro domínios: físico, psicológico, relaçóes sociais e meio ambiente, como apresentado na Tabela 1.

Tabela 1 - Domínios e Facetas do WHOQOL-BREF

\begin{tabular}{l|l}
\hline Domínios & Facetas \\
\hline I - Físico & $\begin{array}{l}\text { Dor e desconforto; energia e fadiga; sono e repouso; mobilidade; } \\
\text { atividades da vida cotidiana; dependência de medicaçáo ou de } \\
\text { tratamentos; capacidade de trabalho }\end{array}$ \\
\hline II - Psicológico & $\begin{array}{l}\text { Sentimento positivos; pensar, aprender, memória de concentração; } \\
\text { autoestima; imagem corporal e aparência; sentimentos negativos; } \\
\text { espiritualidade/religião/crenças pessoais }\end{array}$ \\
\hline III - Relaçóes Sociais & Relaçóes pessoais; atividade sexual; suporte (apoio) social \\
\hline
\end{tabular}




\begin{tabular}{l|l}
\hline Domínios & Facetas \\
\hline IV - Meio Ambiente & $\begin{array}{l}\text { Segurança física e proteção; ambiente no lar; recursos financeiros; } \\
\text { cuidados de saúde e sociais: disponibilidade e qualidade; oportunidades } \\
\text { de adquirir novas informaçóes e habilidades; participação em } \\
\text { oportunidades de recreaçâo/lazer; ambiente físico: poluiçáo/ruído/clima; } \\
\text { transporte }\end{array}$ \\
\hline V - Geral & Percepção da qualidade de vida; satisfação com a saúde \\
\hline
\end{tabular}

Fonte: Elaborado a partir de Fleck (2008).

Para a aplicação do WHOQOL-BREF, foi adotada a cidade de Curitiba, Paraná. A capital paranaense foi escolhida devido ao seu reconhecimento em diversos setores do planejamento urbano, tais como transporte público, resíduos sólidos e desenho urbano. Segundo os dados do Instituto de Pesquisa e Planejamento Urbano de Curitiba (IPPUC), no ano de 2014 a população estimada da cidade era de 1.791 .810 habitante. Desta forma, para a definição da amostra foi utilizada a fórmula do cálculo de amostras para populações infinitas, ou seja, superiores a 100.000 elementos, de Gil (2008).

Considerando um erro de 5\% com 95\% de confiança, chegou-se a um total amostral de 385. Para uma maior efetividade na aplicaçáo, este total foi estratificado proporcionalmente com a população residente de cada bairro da cidade (GIL, 2008), sendo necessário o arredondamento para números inteiros, totalizando em 425 questionários. A apresentaçáo dos dados estratificados e arredondados pode ser observado na Tabela 2.

Tabela 2 - Amostragem de Curitiba em 2014

\begin{tabular}{l|c|c|c|c}
\hline \multicolumn{1}{c|}{ Bairro } & $\begin{array}{c}\text { Populaçáo } \\
\mathbf{2 0 1 5}\end{array}$ & $\begin{array}{c}\text { Porcentagem } \\
\text { referente a cidade de } \\
\text { Curitiba (\%) }\end{array}$ & Estratificaçáo & $\begin{array}{c}\text { Estratificaçáo } \\
\text { Arredondada }\end{array}$ \\
\hline Abranches & 13.680 & 0,763457 & 2,939308 & 3 \\
\hline Água Verde & 51.803 & 2,891097 & 11,13072 & 12 \\
\hline Ahu & 11.593 & 0,646988 & 2,490903 & 3 \\
\hline Alto Boqueirão & 54.281 & 3,029393 & 11,66316 & 12 \\
\hline Alto da Glória & 5.538 & 0,30909 & 1,189996 & 2 \\
\hline Alto da Rua XV & 8.494 & 0,474054 & 1,825108 & 2 \\
\hline Atuba & 16.736 & 0,934015 & 3,595957 & 4 \\
\hline Augusta & 7.321 & 0,408565 & 1,572974 & 2 \\
\hline Bacacheri & 23.886 & 1,333079 & 5,132356 & 6 \\
\hline Bairro Alto & 47.093 & 2,628261 & 10,11881 & 11 \\
\hline Barreirinha & 18.258 & 1,018996 & 3,923134 & 4 \\
\hline Batel & 10.660 & 0,594918 & 2,290436 & 3 \\
\hline Bigorrilho & 28.629 & 1,597776 & 6,151437 & 7 \\
\hline Boa Vista & 31.455 & 1,75547 & 6,75856 & 7 \\
\hline
\end{tabular}




\begin{tabular}{|c|c|c|c|c|}
\hline Bairro & $\begin{array}{l}\text { Populaçáo } \\
2015\end{array}$ & $\begin{array}{c}\text { Porcentagem } \\
\text { referente a cidade de } \\
\text { Curitiba }(\%)\end{array}$ & Estratificação & $\begin{array}{l}\text { Estratificação } \\
\text { Arredondada }\end{array}$ \\
\hline Bom Retiro & 5.040 & 0,2813 & 1,083004 & 2 \\
\hline Boqueirão & 74.313 & 4,147389 & 15,96745 & 16 \\
\hline Butiatuvinha & 13.389 & 0,747247 & 2,876899 & 3 \\
\hline Cabral & 13.385 & 0,747002 & 2,87596 & 3 \\
\hline Cachoeira & 9.696 & 0,541133 & 2,083363 & 3 \\
\hline Cajuru & 97.755 & 5,455683 & 21,00438 & 22 \\
\hline $\begin{array}{l}\text { Campina do } \\
\text { Siqueira }\end{array}$ & 7.379 & 0,41181 & 1,585468 & 2 \\
\hline $\begin{array}{l}\text { Campo } \\
\text { Comprido }\end{array}$ & 30.746 & 1,715936 & 6,606352 & 7 \\
\hline $\begin{array}{l}\text { Campo de } \\
\text { Santana }\end{array}$ & 31.964 & 1,783885 & 6,867956 & 7 \\
\hline Capão da Imbuia & 20.351 & 1,135782 & 4,37276 & 5 \\
\hline Capão Raso & 36.474 & 2,035622 & 7,837144 & 8 \\
\hline Cascatinha & 2.185 & 0,121957 & 0,469536 & 1 \\
\hline Caximba & 2.533 & 0,141387 & 0,544342 & 1 \\
\hline Centro & 38.413 & 2,143796 & 8,253616 & 9 \\
\hline Centro Cívico & 4.787 & 0,267153 & 1,02854 & 2 \\
\hline Cidade Industrial & 176.356 & 9,842337 & 37,893 & 38 \\
\hline Cristo Rei & 13.909 & 0,776251 & 2,988567 & 3 \\
\hline Fanny & 8.548 & 0,477065 & 1,8367 & 2 \\
\hline Fazendinha & 28.547 & 1,593207 & 6,133846 & 7 \\
\hline Ganchinho & 12.112 & 0,675971 & 2,602487 & 3 \\
\hline Guabirotuba & 11.651 & 0,650227 & 2,503373 & 3 \\
\hline Guaíra & 15.058 & 0,84039 & 3,235501 & 4 \\
\hline Hauer & 13.185 & 0,735851 & 2,833027 & 3 \\
\hline Hugo Lange & 3.447 & 0,19235 & 0,740548 & 1 \\
\hline Jardim Botânico & 6.177 & 0,344713 & 1,327146 & 2 \\
\hline Jardim Social & 5.604 & 0,312766 & 1,20415 & 2 \\
\hline Juvevê & 11.655 & 0,650458 & 2,504264 & 3 \\
\hline $\begin{array}{l}\text { Lamenha } \\
\text { Pequena }\end{array}$ & 1.142 & 0,063738 & 0,245392 & 1 \\
\hline Lindóia & 8.642 & 0,482329 & 1,856968 & 2 \\
\hline Mercês & 12.620 & 0,70434 & 2,71171 & 3 \\
\hline Mossunguê & 10.642 & 0,593951 & 2,286712 & 3 \\
\hline Novo Mundo & 44.321 & 2,47353 & 9,523089 & 10 \\
\hline
\end{tabular}




\begin{tabular}{|c|c|c|c|c|}
\hline Bairro & $\begin{array}{l}\text { Populaçáo } \\
2015\end{array}$ & $\begin{array}{c}\text { Porcentagem } \\
\text { referente a cidade de } \\
\text { Curitiba }(\%)\end{array}$ & Estratificação & $\begin{array}{l}\text { Estratificaçáo } \\
\text { Arredondada }\end{array}$ \\
\hline Orleans & 8.310 & 0,463769 & 1,785511 & 2 \\
\hline Parolin & 11.450 & 0,639032 & 2,460273 & 3 \\
\hline Pilarzinho & 28.619 & 1,597207 & 6,149247 & 7 \\
\hline Pinheirinho & 50.574 & 2,822488 & 10,86658 & 11 \\
\hline Portão & 43.129 & 2,407017 & 9,267016 & 10 \\
\hline Prado Velho & 5.833 & 0,325529 & 1,253288 & 2 \\
\hline Rebouças & 14.711 & 0,821015 & 3,160906 & 4 \\
\hline Riviera & 310 & 0,017293 & 0,066576 & 1 \\
\hline Santa Cândida & 34.005 & 1,89781 & 7,306569 & 8 \\
\hline Santa Felicidade & 33.115 & 1,84811 & 7,115225 & 8 \\
\hline Santa Quitéria & 12.161 & 0,678703 & 2,613006 & 3 \\
\hline Santo Inácio & 6.605 & 0,36861 & 1,419149 & 2 \\
\hline Sáo Braz & 23.666 & 1,320769 & 5,084961 & 6 \\
\hline São Francisco & 6.056 & 0,337985 & 1,301244 & 2 \\
\hline São João & 3.326 & 0,185648 & 0,714745 & 1 \\
\hline São Lourenço & 6.451 & 0,360002 & 1,386008 & 2 \\
\hline São Miguel & 4.740 & 0,264512 & 1,018369 & 2 \\
\hline Seminário & 6.719 & 0,37499 & 1,443713 & 2 \\
\hline Sítio Cercado & 118.705 & 6,624841 & 25,50564 & 26 \\
\hline Taboão & 3.572 & 0,199379 & 0,767609 & 1 \\
\hline Tarumã & 8.321 & 0,46439 & 1,787901 & 2 \\
\hline Tatuquara & 56.143 & 3,133337 & 12,06335 & 13 \\
\hline Tingüí & 12.502 & 0,697732 & 2,68627 & 3 \\
\hline Uberaba & 74.897 & 4,179956 & 16,09283 & 17 \\
\hline Umbará & 19.732 & 1,101259 & 4,239849 & 5 \\
\hline Vila Izabel & 11.770 & 0,656892 & 2,529033 & 3 \\
\hline Vista Alegre & 11.507 & 0,64218 & 2,472394 & 3 \\
\hline Xaxim & 57.786 & 3,225002 & 12,41626 & 13 \\
\hline Curitiba & 1.791 .810 & 100 & 385 & 425 \\
\hline
\end{tabular}

Fonte: Elaborado pela própria autora.

De acordo com a OMS o cálculo e as análises da pesquisa devem ser realizados através de um programa, com a finalidade de anular possíveis erros. Para realização dos cálculos, foi adotado o Software Microsoft Office Excel 2010, conforme a ferramenta desenvolvida por Pedroso, Pilatti e Reis (2010). A sintaxe desenvolvida verifica os valores de entrada, recodifica as questóes 3, 4 e 26 do questionário (as quais estão com a pontuação contrária), 
realiza a média por domínios, apresenta os resultados em escala de 0 a 100 e elimina os questionários que possuem mais do que seis questóes incompletas. Além disto, a avaliação destes dados é realizada partir da escala de Likert, a qual possui uma variação de 1 a 5 (QUADRO 1).

\section{Quadro 1 - Escala WHOQOL}

\begin{tabular}{|c|c|c|c|c|}
\hline Muito ruim & Ruim & $\begin{array}{c}\text { Nem ruim, } \\
\text { nem boa }\end{array}$ & Boa & Muito boa \\
\hline 1 & 2 & 3 & 4 & 5 \\
\hline
\end{tabular}

Fonte: Elaborado a partir de OMS (1994).

A escala de Likert é utilizada principalmente em estudos que medem percepçóes e interesses. Ela possibilita a obtenção de respostas mais próximas da realidade por meio das afirmaçóes dos respondentes (SILVA JUNIOR. COSTA, 2014).

\subsection{Aplicação do Método WHOQOL-BREF}

O WHOQOL-BREF, considerado um instrumento simplificado, foi adotado para a realização da presente pesquisa, tendo sua aplicação no segundo semestre do ano de 2014. Ressalta-se que a aplicação dos questionários ocorreu, primeiramente, por meio da ferramenta onlinepesquisa, de forma a viabilizar em custo e tempo. A pesquisa online permaneceu disponível até atingir a meta de 425 questionários, sendo parte deles $(35,8 \%)$ sido realizado manualmente. A necessidade por aplicação manual se deu devido à falta de comunicação com alguns bairros, de tal modo que a pesquisa não atingiu o total de pessoas esperadas no primeiro momento. Para esta complementaçáo de dados, foi realizado quatro dias de atividade externa.

Cada respondente recebeu uma explicação sobre o objetivo da pesquisa, como orientado pela OMS, respondendo seu formulário em particular. Ressalva às situaçóes onde os indivíduos não conseguiram responder o questionário sozinhos, geralmente devido a problemas de visão e, raramente, devido ao analfabetismo, onde as perguntas foram lidas sem meios de interferir nas respostas. Vale ressaltar ainda que nestas ocasióes a questão 21 , não foi perguntada de forma a evitar constrangimentos de ambas às partes. Para os casos onde as pessoas não entenderam, esqueceram ou não quiseram responder alguma pergunta, foi inserido um código para diferenciar das questôes respondidas. Esta metodologia é orientada pela OMS de forma a não interferir nos resultados gerais.

Ressalta-se que a criação do presente método teve a finalidade de apresentar um novo instrumento de medição da qualidade de vida no âmbito da saúde. Desta forma, a escolha do mesmo para aplicação em um cenário diferente trouxe algumas dificuldades durante o processo. A primeira delas está relacionada à quantidade de questionários a serem aplicados, sendo que os mesmos são extensos, e é necessária a aplicação de um número elevado para minimizar as chances de erro. Esta situação tem algumas complicações quando a amostra é estratificada, pois cada ponto da cidade deve ser analisado conforme os cálculos prescritos na literatura. Isto traz como limitação a aplicação espacial uniformemente dispersada, de modo 
que o tempo necessário para a realização dos questionários poderia dobrar se realizado desta forma. Por fim, destaca-se também a escala adotada pela OMS. A adaptação dela para uma interpretação visual com figuras ou cores pode auxiliar quanto ao tempo de resposta de cada participante, facilitando na avaliação de cada situação.

\section{RESULTADOS E DISCUSSÓES}

Por meio da utilização do método WHOQOL-BREF, foi realizado o estudo da qualidade de vida da cidade de Curitiba com a aplicação de 425 questionários. A partir destes resultados, é possível avaliar a qualidade de vida da cidade tanto em sua totalidade, quanto por meios específicos, ficando fácil de identificar os principais problemas e como solucioná-los a partir da visão da população local. O Gráfico 1 apresenta a caracterização dos entrevistados, sendo composta por $50,8 \%$ de mulheres e $49,2 \%$ de homens, com uma faixa etária variando de 18 a 80 anos.

Com a estratificação por bairros, a aplicação da pesquisa se deu por meio eletrônico e manual, obtendo-se a média geral e a média por domínios. Considerando a escala de Likert (variação de 1 a 5), a média geral obtida foi de 3,62. Dentre as questóes, as que tiveram menores resultados foram sobre recurso financeiro (Q12), poluição (Q9), oportunidades de lazer (Q14) e segurança (Q8), com 3,24, 3,27, 3,27 e 3,28 respectivamente. Os melhores resultados foram sobre locomoção (Q15), sentido da vida (Q6), avaliação pessoal da qualidade de vida em geral (Q1) e satisfação com amigos e familiares (Q20) com 4,31, $4,16,3,92$ e 3,88 respectivamente.

Gráfico 01 - Caracterização dos entrevistados do WHOQOL-BREF

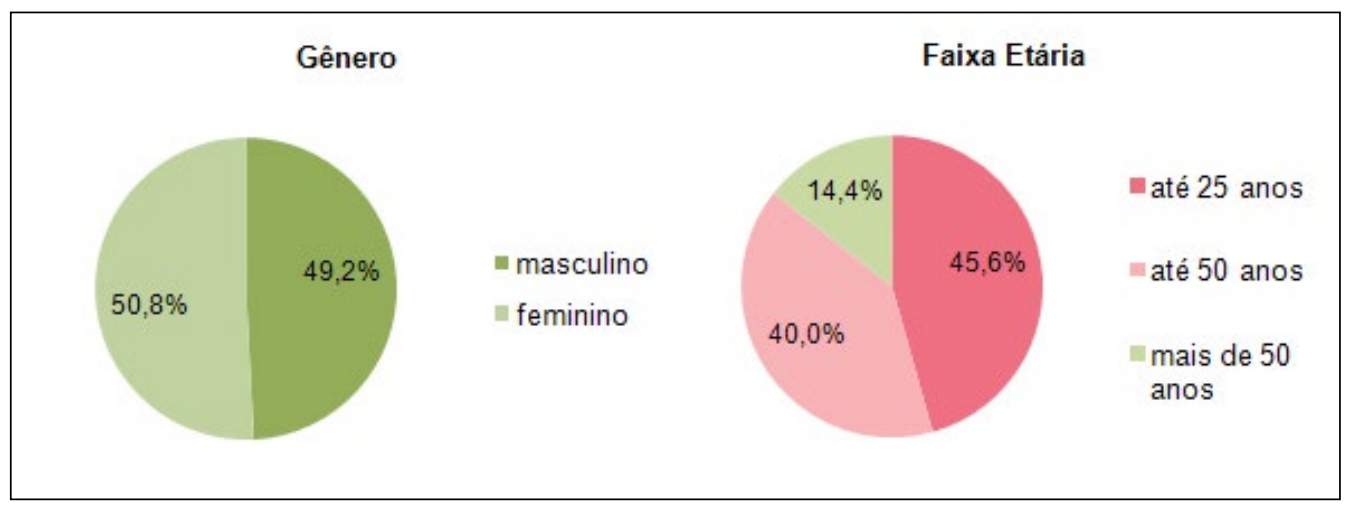

Fonte: Elaborado pela própria autora.

A média de variação das respostas entre os entrevistados foi de 28,98\%. As maiores variaçóes se deram nos assuntos relacionados à vida sexual (Q21), dores (Q3), tratamento médico (Q4) e serviços de saúde (Q24), com 47,89\%, 39,56\%, 37,81\% e 35,29\% respectivamente. As menores variaçóes estão relacionadas com auto avaliação da qualidade de vida (Q1), locomoção (Q15), sentido da vida (Q6) e disponibilidade de informaçóes (Q13), com 18,29\%, 19,91\%, 20,30\% e 24,22\% respectivamente (GRÁFICO 2). 
Ao considerar as médias por domínios, obteve-se uma variação de 3,43 a 3,77. O domínio do meio ambiente apresentou o menor resultado, com 3,43. Ele aborda questóes sobre segurança diária, poluição, transporte, saúde, acesso a informação e moradia. $\mathrm{O}$ segundo menor resultado se deu no domínio relaçóes sociais com 3,65. Tal domínio considera questôes sobre satisfação com amigos e familiares, apoio e vida sexual. Os domínios físico e psicológico apresentaram média de 3,71, sendo que o primeiro trata questóes de dores, locomoção e satisfação pessoal, enquanto o outro aborda o sentido da vida, concentração, aceitação e sentimentos negativos. A maior média trata-se da autoavaliação sobre a qualidade de vida, onde alcançou 3,77 .

\section{Gráfico 2 - Resultado Geral}

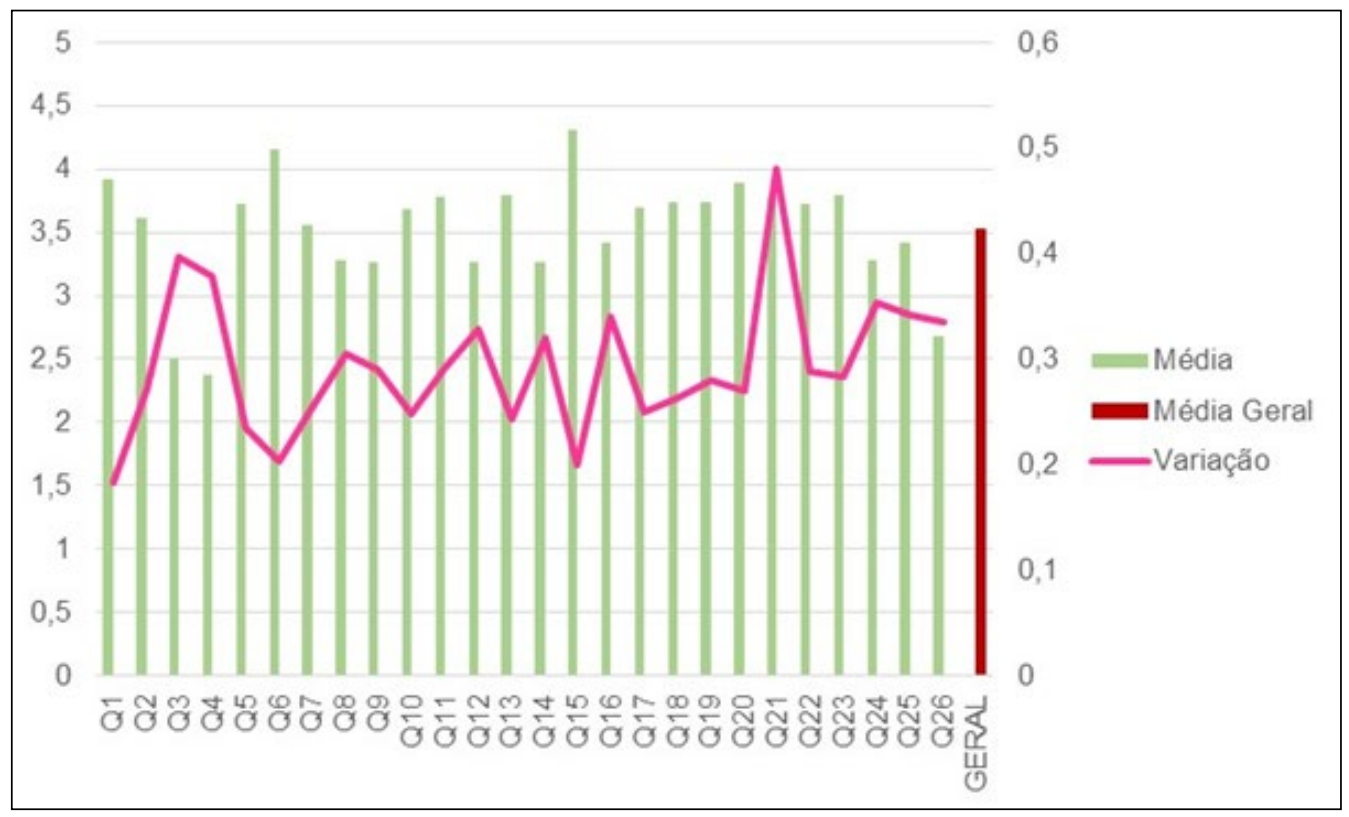

Fonte. Elaborado pela própria autora.

Ao analisar a média de variação, observa-se apenas $1 \%$ para a avaliação geral. Em relação a cada domínio, a autoavaliação resultou em uma diferença de $4 \%$ entre a opiniáo das pessoas e sua percepção geral. Enquanto os domínios de relaçôes sociais e de meio ambiente obtiveram uma variação média de $6 \%$, os domínios físico e psicológico obtiveram uma variação de $7 \%$. Pode-se observar que a partir da percepçáo das pessoas, tanto a avaliaçáo geral da qualidade de vida, quanto a avaliação por domínios, apresentam resultados entre os valores 3 e 4. Desta forma, são classificas entre "nem ruim, nem boa" e "boa" conforme a escala de Likert. A Tabela 3 apresenta os resultados pelos domínios em que o índice é subdividido.

Com os resultados alcançados, foi criado o mapa de QV, baseado no método do WHOQOL-BREF para melhor visualização dos dados. O mapa de qualidade de vida da cidade de Curitiba pode ser observado na Figura 1. Destaca-se que dos 75 bairros de 
Curitiba, apenas 45,3\% encontram-se em uma classificação "boa". Em pouco mais da metade $(54,7 \%)$, a qualidade de vida foi classificada como "nem ruim, nem boa". Tendo em vista que Curitiba é conhecida no país e no mundo por usas premiaçóes e pelos seus projetos de sustentabilidade, o resultado sobre a satisfação da população perante a cidade é alarmante. Sendo assim, destaca-se a falta de integração entre a sociedade e os governantes nos processos de planejamento, situação que poderia auxiliar em decisóes mais certeiras para benefício não apenas dos municípios, mas também da qualidade de vida de cada cidadão.

Tabela 3 - Resultados por Domínios do WHOQOL-BREF

\begin{tabular}{l|c|c|c|c|c|c}
\hline \multicolumn{1}{c|}{ Domínio } & Média & $\begin{array}{c}\text { Desvio } \\
\text { Padrão }\end{array}$ & $\begin{array}{c}\text { Coef. De } \\
\text { Variação }\end{array}$ & $\begin{array}{c}\text { Valor } \\
\text { Mínimo }\end{array}$ & $\begin{array}{c}\text { Valor Má- } \\
\text { ximo }\end{array}$ & $\begin{array}{c}\text { Ampli- } \\
\text { tude }\end{array}$ \\
\hline Físico & 3,71 & 0,27 & 7 & 3,41 & 4,31 & 0,89 \\
\hline Psicológico & 3,71 & 0,25 & 7 & 3,32 & 4,16 & 0,84 \\
\hline Relaçôes Sociais & 3,65 & 0,23 & 6 & 3,33 & 3,88 & 0,55 \\
\hline Meio Ambiente & 3,43 & 0,21 & 6 & 3,24 & 3,80 & 0,55 \\
\hline Autoavaliação & 3,77 & 0,15 & 4 & 3,61 & 3,92 & 0,31 \\
\hline GERAL & $\mathbf{3 , 6 2}$ & $\mathbf{0 , 0 4}$ & $\mathbf{1 , 1}$ & $\mathbf{3 , 2 4}$ & $\mathbf{4 , 3 1}$ & $\mathbf{1 , 0 6}$ \\
\hline
\end{tabular}

Fonte. Elaborado pela própria autora.

Outro ponto importante a se destacar é que a aplicação do presente método pode ser considerada fácil, apesar do alto valor da amostra obtida. Porém, ao analisar os trabalhos publicados, percebe-se que sua utilização é realizada para a área de saúde, sendo difícil encontrar projetos em outros segmentos. No Brasil e no mundo, o WHOQOL-BREF vem sendo aplicado desde 1998, segundo a base de dados da Literatura Latino-Americana e do Caribe em Ciências da Saúde (LILACS) e do Medical Literature Analysis and Retrieval System Online (MEDLINE), sendo estas pesquisas concentradas especificamente na área médica (KLUTHCOVSKYI; KLUTHCOVSKYI, 2010).

Cada publicação sobre a qualidade de vida nos meios urbanos apresenta seu próprio perfil, com seus próprios métodos e indicadores. Exemplos disto são os projetos elaborados para as cidades de Palmas/Tocantins, e do Porto, em Portugal. A avaliação da qualidade de vida em Palmas ocorreu por meio de indicadores relacionados à habitação, a fim de encontrar os pontos de vulnerabilidade socioambiental da cidade. Diferentemente do método adotado para se mediar a qualidade de vida em Curitiba, a cidade de Palmas foi avaliada de maneira censitária e a partir da percepçáo dos autores Kran, Poley e Ferreira (2006). Vale destacar que houve correlaçóes entre os resultados encontrados com o domínio de meio ambiente da presente pesquisa, tendo-se concluído a necessidade de melhorias quanto ao saneamento, resíduos e poluição (KRAN; POLEY; FERREIRA, 2006). 
Figura 1 - Mapa de Qualidade de Vida de Curitiba

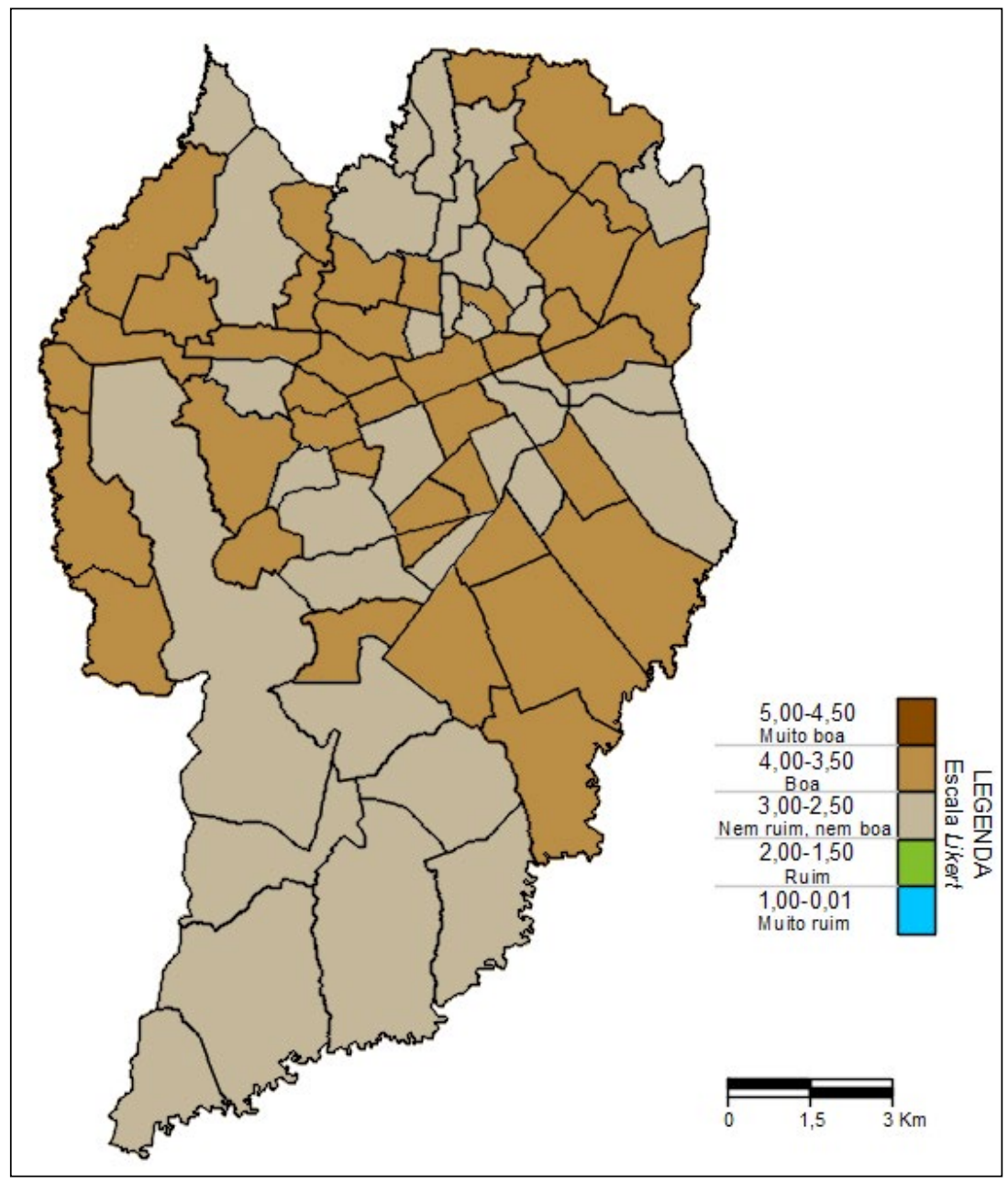

Fonte. Elaborado pela própria autora.

O projeto realizado na Cidade do Porto, em Portugal, teve uma finalidade semelhante ao que foi desenvolvido na cidade de Curitiba. A pesquisa se baseou em 2400 residentes para avaliar a percepçáo dos cidadãos. $\mathrm{O}$ interessante a se destacar é que assim como os resultados obtidos na aplicaçáa do WHOQOL-BREF, o método utilizado na Cidade do Porto permitiu destacar os principais fatores que as pessoas consideram importantes para se ter a qualidade de vida na cidade. Além das questôes básicas de transporte, segurança e habitação, outros aspectos levantados em ambas as localidades foram a existência de áreas vedes e os espaços urbanos sem poluição (SANTOS. MARTINS. BRITO, 2005).

Diante destes cenários, cabe destacar também o projeto elaborado por Machado (2004) para a cidade de Curitiba, o qual trouxe uma visão aproximada ao objetivo da aplicação do WHOQOL-BREF. $\mathrm{O}$ autor não considerou sua análise em relação ao Planejamento Urbano, mas sim, sob a ótica do Desenvolvimento e das Políticas Públicas 
pelo método Genebrino. Com a realização da análise de quatro dimensões (saúde, educação, habitação e transporte), foi possível identificar as áreas da cidade com maior satisfação de qualidade de vida. Estas avaliaçóes permitem destacar a importância de se considerar a percepção da população como base nas tomadas de decisão, independentemente do método utilizado para análise.

\section{CONSIDERAÇÓES FINAIS}

O presente artigo apresentou uma nova percepçáo sobre o uso de indicadores de qualidade de vida a partir da opiniáo dos moradores da cidade de Curitiba. Utilizando o método WHOQOL-BREF, os 425 cidadãos que responderam o presente instrumento de pesquisa, puderam avaliar a cidade destacando os principais pontos de problemas e melhorias para as regióes em que moram.

O problema mais citado pelos moradores está relacionado aos recursos financeiros, o que nos mostra o quanto a classe social interfere na vida das pessoas. As situaçóes que trazem desconforto estão relacionadas à poluição da cidade: falta de saneamento para comunidades ribeiras, falta de lixeiras, lixo nos rios e no chão.

Outra falha identificada é o déficit de locais para lazer. Ressalta-se que a maior concentração de parques e bosques da cidade está localizada na região nordeste (regional Boa Vista), fazendo com que moradores tenham que se deslocar por um trajeto longo para poder usufruir das principais áreas verdes da cidade.

Por fim, a segurança é outro fator levantado pelos entrevistados, tendo em vista que o grau de violência em Curitiba tem subido a cada ano, deixando a população alarmada sobre a atual situação da cidade.

É importante destacar que além dos pontos negativos, as pessoas também tiveram a oportunidade de expor sugestóes de melhorias para as regióes que moram. Um destaque é dado quanto uma solução para o trânsito nos horários de pico: o retorno do trem de passageiros que ligue as regióes ao centro da cidade.

Deste modo, conclui-se que a opiniáo das pessoas deve ser levada em consideração na avaliaçáo do desenvolvimento da cidade, de forma que este possa ser um novo instrumento para formulação de políticas públicas.

\section{REFERÊNCIAS}

BARBOSA, Gisele Silva. O Desafio do Desenvolvimento Sustentável. v. 1, n. $04.4^{\mathrm{a}}$ ed. Rio de Janeiro: Revista Visóes, 2008.

DEMO, Pedro. Pobreza Política: Polêmicas do Nosso Tempo. $6^{\circ}$ ed. Campinas: Editora Autores Associados, 2001.

DUARTE, Fabio. Planejamento Urbano. Curitiba: Ibpex, 2007. 
GILL, Thomas. FEINSTEIN, Alvan. A critical appraisal of the quality of quality-oflife measurements. v.272, n.8. Chicago: JAMA, 1994.

HERCULANO, Selene. A Qualidade de Vida e seus Indicadores. In: PORTO, Marcelo Firpo de Souza. FREITAS Carlos Machado. Qualidade de vida e riscos ambientais. Niterói: Eduff, 2000.

IPPUC. Planilha de Projeçáo da População: 2010 a 2040.

FERNANDES, António Teixeira. As sociedades e a qualidade de vida: tendências actuais. Portugal: Celta Editora, 2000.

FLECK, Marcelo Pio de Almeida (org). A avaliaçáo de qualidade de vida: guia para profissionais de saúde. Porto Alegre: ARTMED, 2008.

FLECK, Marcelo Pio de Almeida. LEAL, Ondina Fachel. LOUZADA, Sérgio. XAVIER, Marta. CHACHAMOVICH, Eduardo. VIEIRA, Guilherme. SANTOS, Lyssandra dos. PINZON, Vanessa. Desenvolvimento da versáo em português do instrumento deavaliaçáo de qualidade de vida da OMS (WHOQOL-100). Revista Brasileira de Psiquiatria, v.21, n.01, 1999.

GRAZIA, Grazia de. QUEIROZ, Lêda Lucia de. MOTTA, Athayde. SANTOS, Alexandre Mello. O desafio da sustentabilidade urbana. Rio de Janeiro: FASE, 2001. Série Cadernos Temáticos, n. 5. E-book disponível em: <https://books.google.com.br/ books?id=wUxHAAAAYAAJ\&redir_esc=y>.

IPPUC. Memória da Curitiba Urbana. Curitiba, Instituto de Pesquisa e Planejamento Urbano de Curitiba, 1992.

KLUTHCOVSKYI, Ana Cláudia. KLUTHCOVSKYI, Fábio Aragão. O WHOQOLbref, um instrumento para avaliar qualidade de vida: uma revisão sistemática. Guarapuava: UNICENTRO, 2010.

KRAN, Faida. POLEY, Frederico. FERREIRA, Martins. Qualidade de vida na cidade de Palmas - TO: uma análise através de indicadores habitacionais e ambientais urbanos. vol. 9 n. 2. Campinas: Ambiente \& Sociedade, 2006.

MACHADO, Paulo Henrique Battaglin. Curitiba, A Qualidade e A Vida. PPGICH/ UFSC, 2004.

MENEZES, Claudino Luiz. Desenvolvimento Urbano e Meio Ambiente: A Experiência de Curitiba. $2^{a}$ ed. Campinas: Papirus, 2001.

MINAYO, Maria Cecília de Souza. HARTZ, Zulmira Maria de Araújo. BUSS, Paulo Marchiori. Qualidade de vida e saúde: um debate necessário. Ciência \& Saúde Coletiva, v.05, n.01, 2000. 
RUFFINO NETTO, Antônio. Qualidade de vida: compromisso histórico da epidemiologia. In: LIMA E COSTA, M. F; SOUSA, R. P. (Org). Qualidade de vida: compromisso histórico da epidemiologia. Belo Horizonte: Coopmed/Rio de Janeiro: Abrasco, 1994. p. 11-18.

NUSSBAUM, Martha. SEN, Amartya Kumar. La calidad de vida. Colombia: Fondo de Cultura Económica: 1996.

OMS - Organização Mundial de Saúde. Versão em português dos instrumentos de avaliação de qualidade de vida. Programa de Saúde Mental. Genebra: Grupo Whoqol, 1994. Disponível em: <http://www.ufrgs.br/psiquiatria/psiq/whoqol.html>. Acesso em: 07 abr. 2015.

PEDROSO, Bruno. PILATTI, Luiz Alberto. REIS, Dálcio Roberto. Cálculo dos escores e estatística descritiva do WHOQOL-bref através do Microsoft Excel. v.02, n.01. Curitiba: Revista Brasileira de Qualidade de Vida, 2010.

PEREIRA, Érico Felden. TEIXEIRA, Clarissa Stefani. SANTOS, Anderlei. Qualidade de vida: abordagens, conceitos e avaliação. v.26, n.2. São Paulo: Revista Brasileira de Educação Física e Esporte, 2012.

PREFEITURA Municipal de Curitiba. ONU aponta Curitiba como referência nas áreas de planejamento urbano e transporte. Curitiba, 2011. Disponível em: <http:// www.urbs.curitiba.pr.gov.br/noticia/onu-aponta-curitiba-como-referencia-nasareas- deplanejamento-urbano-e-transporte>. Acesso em 17 abr. 2015.

PUPPI, Ildefonso C. Estruturação sanitária das cidades. Curitiba, Universidade Federal do Paraná; São Paulo, CETESB, 1981. 330 p.

SANTOS, Célia Samarina Vilaça de Brito. RIBEIRO, José Luís Pais. A Qualidade de Vida do Doente Oncológico: Revisão da Bibliografia. Portugal: Revista Referência, n.07, 2001.

SANTOS, Luis Delfim. MARTINS, Isabel. BRITO, Paula. O conceito de qualidade de vida urbana na perspectiva dos residentes na cidade do Porto. n. 9. Porto: Estudos Regionais, 2005.

SCHNEIDER, Sérgio. FREITAS, Tanise Dias. Qualidade de Vida, Diversificação e desenvolvimento: referências práticas para análise do bem-estar no meio rural. v.02, n.01. Olhares Sociais, 2013.

SILVA JUNIOR, Severino Domingos da. COSTA, Francisco José da. Mensuração e Escalas de Verificaçáo: uma Análise Comparativa das Escalas de Likert e Phrase Completion. XVII SEMEAD Seminários em Administração. São Paulo: USP, 2014 
WHO. WHOQOL: Measuring Quality of Life. Division of Mental Health and Prevention of Substance Abuse, World Health Organization. 1997.

WILHEIM, Jorge. Qualidade de Vida e Tecnologias Alternativas. Seminário de Tecnologias Apropriadas para os Assentamentos Humanos. São Paulo, 1982.

\section{ANEXO A - QUESTIONÁRIO WHOQOL-BREF}

\begin{tabular}{|c|c|c|c|c|c|c|}
\hline \multicolumn{7}{|c|}{ Instruçóes } \\
\hline \multicolumn{7}{|c|}{$\begin{array}{l}\text { Este questionário é sobre como você se sente a respeito de sua qualidade de vida, saúde e outras áreas de } \\
\text { sua vida. Por favor, responda a todas as questóes. Se você não tem certeza sobre que resposta dar em uma } \\
\text { questáo, por favor, escolha entre as alternativas a que lhe parece mais apropriada. Esta, muitas vezes, poderá } \\
\text { ser sua primeira escolha }\end{array}$} \\
\hline \multicolumn{7}{|c|}{$\begin{array}{l}\text { Por favor, tenha em mente seus valores, aspiraçóes, prazeres e preocupaçóes. Nós estamos perguntando o que } \\
\text { você acha de sua vida, tomando como referência as duas últimas semanas. }\end{array}$} \\
\hline & & $\begin{array}{l}\text { Muito } \\
\text { ruim }\end{array}$ & Ruim & $\begin{array}{l}\text { Nem ruim, } \\
\text { nem boa }\end{array}$ & Boa & Muito boa \\
\hline \multirow[t]{2}{*}{1} & $\begin{array}{l}\text { Como você avaliaria sua } \\
\text { qualidade de vida? }\end{array}$ & 1 & 2 & 3 & 4 & 5 \\
\hline & & $\begin{array}{l}\text { Muito } \\
\text { insatisfeito }\end{array}$ & Insatisfeito & $\begin{array}{l}\text { Nem satisfeito, } \\
\text { nem insatisfeito }\end{array}$ & Satisfeito & Muito satisfeito \\
\hline 2 & $\begin{array}{l}\text { Quão satisfeito(a) você está } \\
\text { com sua saúde? }\end{array}$ & 1 & 2 & 3 & 4 & 5 \\
\hline
\end{tabular}

\begin{tabular}{|l|l|l|l|l|l|l|}
\hline \multicolumn{2}{|c|}{ As questóes seguintes sáo sobre o quanto você tem sentido algumas coisas nas últimas semanas } \\
\hline \multicolumn{2}{|l|}{} & Nada & $\begin{array}{l}\text { Muito } \\
\text { pouco }\end{array}$ & $\begin{array}{l}\text { Mais ou } \\
\text { menos }\end{array}$ & Bastante & Extremamente \\
\hline 3 & $\begin{array}{l}\text { Em que medida você acha que } \\
\text { sua dor física o impede de fazer } \\
\text { o que você precisa? }\end{array}$ & 1 & 2 & 3 & 4 & 5 \\
\hline 4 & $\begin{array}{l}\text { O quanto você precisa de } \\
\text { algum tratamento médico para } \\
\text { levar sua vida diária? }\end{array}$ & 1 & 2 & 3 & 4 & 5 \\
\hline 5 & Quanto você aproveita a vida? & 1 & 2 & 3 & 4 & 5 \\
\hline 6 & $\begin{array}{l}\text { Em que medida você acha que } \\
\text { sua vida tem sentido? }\end{array}$ & 1 & 2 & 3 & 4 & 5 \\
\hline 7 & $\begin{array}{l}\text { O quanto você consegue se } \\
\text { concentrar? }\end{array}$ & 1 & 2 & 3 & 4 & 5 \\
\hline 8 & $\begin{array}{l}\text { Quâo seguro você se sente em } \\
\text { sua vida diária? }\end{array}$ & 1 & 2 & 3 & 4 & 5 \\
\hline 9 & $\begin{array}{l}\text { Quão saudável é seu ambiente } \\
\text { físico (clima, barulho, poluição, } \\
\text { atrativos)? }\end{array}$ & 1 & 2 & 3 & 4 & 5 \\
\hline
\end{tabular}




\begin{tabular}{|c|c|c|c|c|c|c|}
\hline \multicolumn{7}{|c|}{$\begin{array}{l}\text { As questóes seguintes sáo sobre quáo completamente você tem sentido ou é capaz de fazer certas coisas } \\
\text { nestas últimas duas semanas }\end{array}$} \\
\hline & & Nada & $\begin{array}{l}\text { Muito } \\
\text { pouco }\end{array}$ & Médio & Muito & Completamente \\
\hline 10 & $\begin{array}{l}\text { Você tem energia suficiente para seu dia- } \\
\text { a-dia? }\end{array}$ & 1 & 2 & 3 & 4 & 5 \\
\hline 11 & $\begin{array}{l}\text { Você é capaz de aceitar sua aparência } \\
\text { física? }\end{array}$ & 1 & 2 & 3 & 4 & 5 \\
\hline 12 & $\begin{array}{l}\text { Você tem dinheiro suficiente para suas } \\
\text { necessidades? }\end{array}$ & 1 & 2 & 3 & 4 & 5 \\
\hline 13 & $\begin{array}{l}\text { Quáo disponíveis para você estão as } \\
\text { informaçôes que precisa no seu dia-a-dia? }\end{array}$ & 1 & 2 & 3 & 4 & 5 \\
\hline 14 & $\begin{array}{l}\text { Em que medida você tem oportunidades } \\
\text { de atividades de lazer? }\end{array}$ & 1 & 2 & 3 & 4 & 5 \\
\hline
\end{tabular}

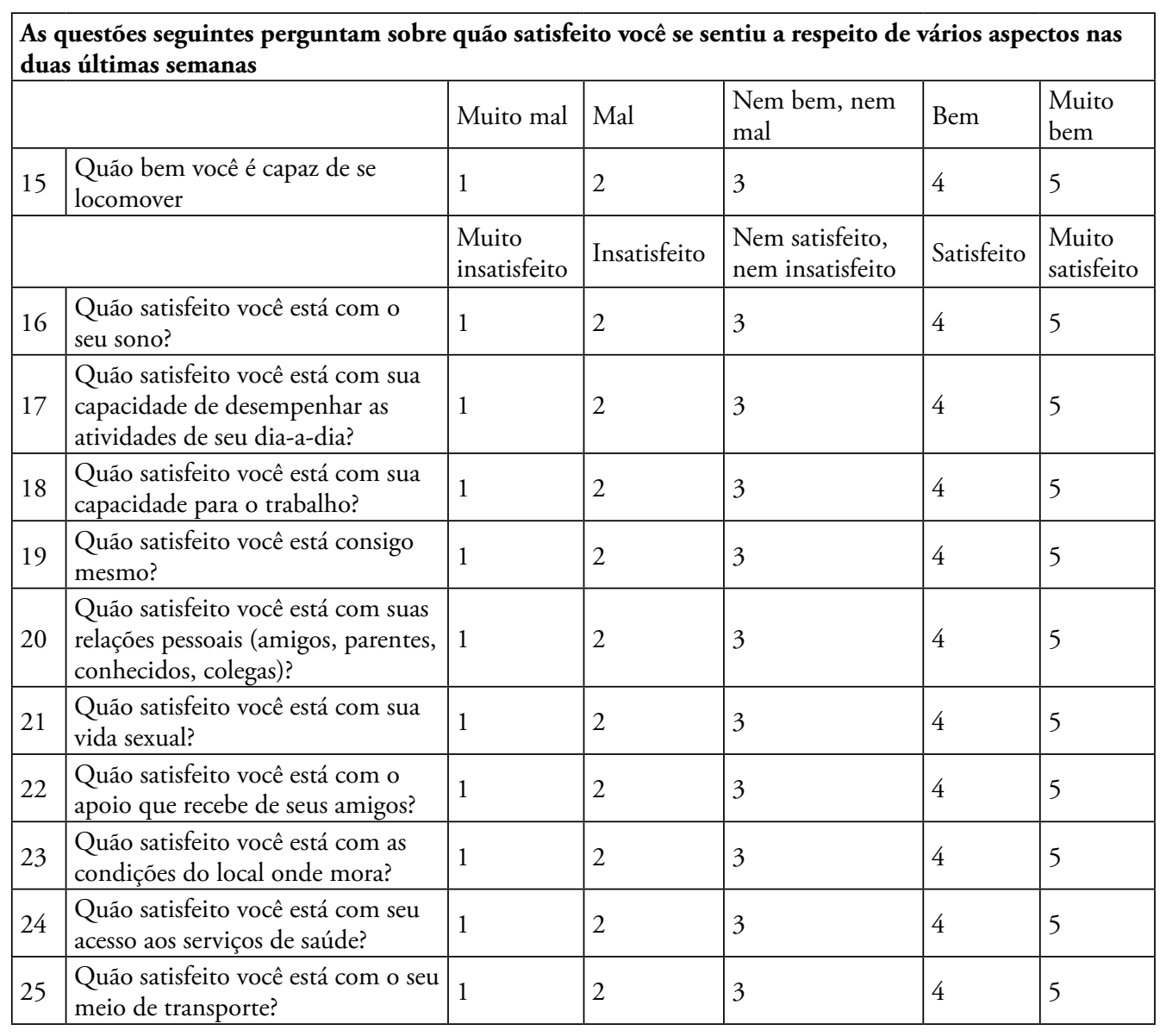


A questáo seguinte refere-se a com que frequência você sentiu ou experimentou certas coisas nas últimas duas semanas

\begin{tabular}{|l|l|l|l|l|l|l|}
\hline \multicolumn{2}{|c|}{} & Nunca & $\begin{array}{l}\text { Algumas } \\
\text { vezes }\end{array}$ & Frequentemente & $\begin{array}{l}\text { Muito } \\
\text { frequentemente }\end{array}$ & Sempre \\
\hline 26 & $\begin{array}{l}\text { Com que frequência você tem } \\
\text { sentimentos negativos tais como } \\
\text { mau-humor, desespero, ansiedade, } \\
\text { depressáo? }\end{array}$ & 1 & 2 & 3 & 4 & 5 \\
\hline
\end{tabular}

